\title{
¿De qué manera puede el patrimonio cultural convertirse en herramienta para la lucha contra el cambio climático?
}

\author{
Teófilo Victoria, Ricardo López | Facultad de Arquitectura, Universidad de Miami
}

URL de la contribución <www.iaph.es/revistaph/index.php/revistaph/article/view/4994>

Hoy por hoy, por lo menos en nuestra alterada memoria como consecuencia de haber sido testigos del desastre que causó el huracán Dorian a los pueblos y ciudades en las islas del cayo de los Ábacos, en la Mancomunidad de las Bahamas, en vez de preguntarnos cómo afecta el cambio climático al patrimonio cultural, la pregunta fundamental es: cuáles son las características constructivas de los asentamientos históricos responsable por un desempeño superior. Es decir, qué nos enseña y cómo documentar el patrimonio urbano y arquitectónico (en este caso, los asentamientos históricos del Gran Caribe) en términos de resiliencia frente a cambios hidrológicos y al aumento de la frecuencia e intensidad de huracanes en el Atlántico sur y en el Gran Caribe.

El 1 de septiembre de 2019, a las 12:00 PM (UTC) el huracán Dorian, tormenta de Categoría 5 (la clasificación más alta en la escala de huracanes de SaffirSimpson), alcanzó tierra en el cayo de Elbow Cay, en el archipiélago de los Ábacos en las Bahamas. Con vientos sostenidos de $185 \mathrm{mph}(297 \mathrm{~km} / \mathrm{h})$ y presión barométrica central de un mínimo de 910 mbar, Dorian es el huracán más fuerte registrado que azota ha azotado las Bahamas desde que comenzaron los registros en 1851. Está a la par con el peor huracán del siglo XX, el huracán del Día del Trabajo de 1935, por los vientos sostenidos más altos en un huracán del Atlántico al tocar tierra; y, por la misma métrica, también es el huracán más fuerte del Atlántico desde el huracán Wilma en 2005. Más importante, tal vez, Dorian constituye el mayor desastre en la historia de las Bahamas.

Ese domingo la tormenta hizo tierra en el asentamiento histórico de Hope Town en el cayo Elbow Cay antes de proseguir a Marsh Harbour, capital del archipiélago de los Ábacos y, el lunes, a Freeport, capital de la isla conti-

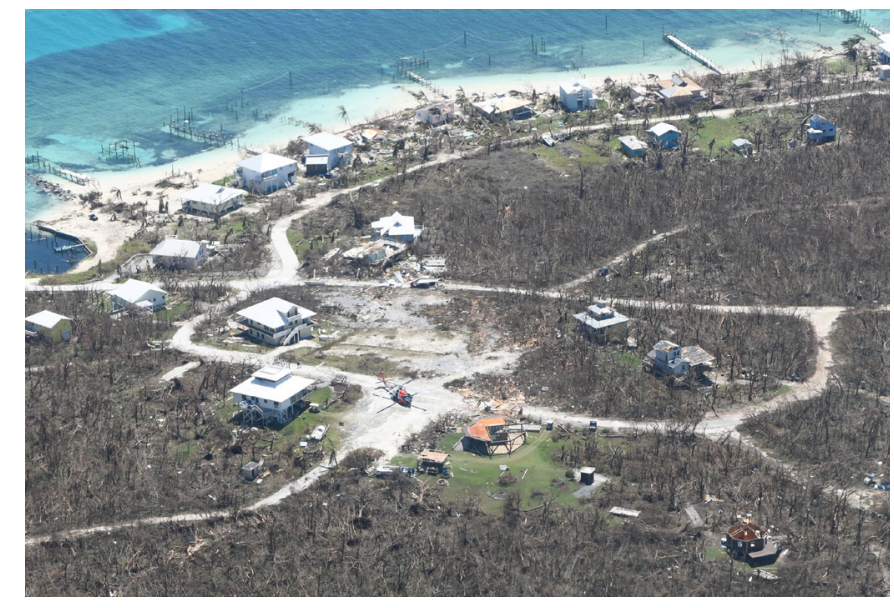

Cerca de Marsh Harbour, Bahamas, el 5 de septiembre de 2019 | foto Coast Guard News (Hunter Medley, suboficial de la Guardia Costera de Estados Unidos)

gua de Gran Bahamas. El huracán causó una marejada de 23 pies $(7.01 \mathrm{~m})$ sobre el nivel del mar y depositó 3 pies $(0.914 \mathrm{~m})$ de aguas torrenciales sobre las islas causando estragos incalculables. Milagrosamente hubo un mínimo de pérdida de vidas, pero la ciudad de Marsh Harbour fue destruida por completo y tuvo que ser evacuada el día después de la tormenta mientras que la otra ciudad moderna, Freeport, en la isla de Gran Bahama, fue rendida inoperable por las inundaciones.

Sin embargo, para asombro de todos, los asentamientos históricos construidos en madera hace dos siglos resistieron el azote de la tormenta, tanto los vientos como el embate de la marejada y las inundaciones por las lluvias, de una forma superior a las ciudades de la posguerra construidas en concreto armado.

Estos pueblos, Hope Town entre ellos, fundados a finales del siglo XVIII por Loyalist huyéndole a la revolución 


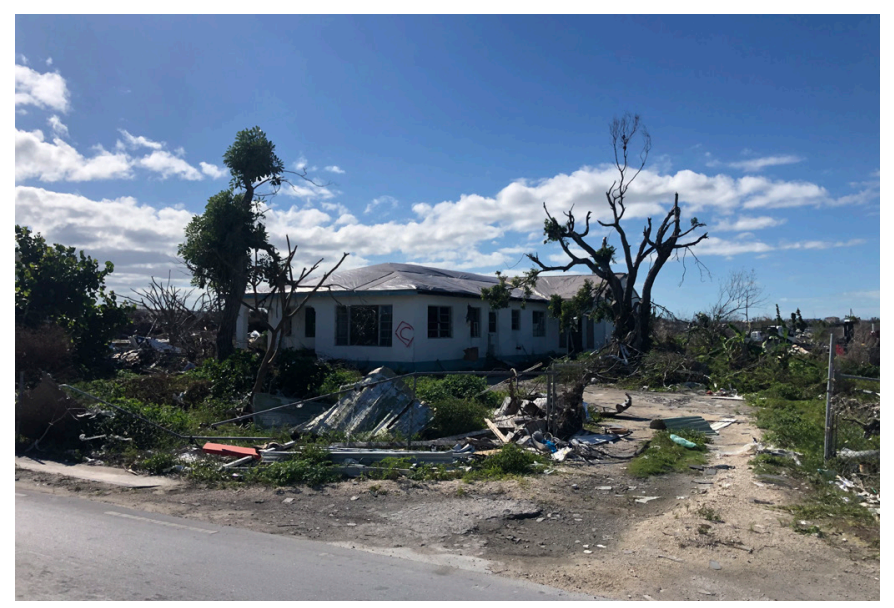

Marsh Harbour, Bahamas, tras el huracán Dorian en 2019 | foto Unitarian Universalist Service Committee

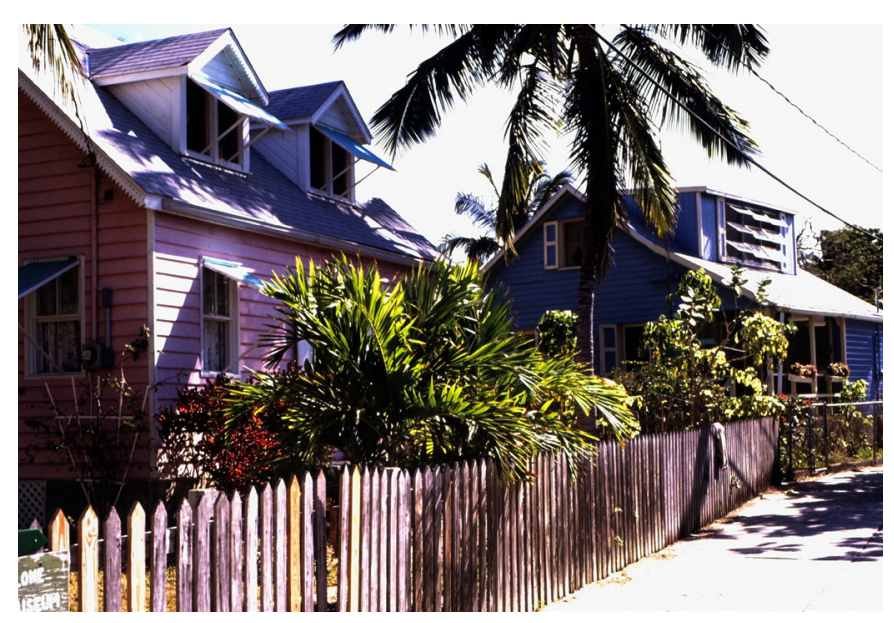

Hope Town, Elbow Cay, Bahamas 1989 | foto Rüdiger Stehn

americana de 1776, constituyen un patrimonio cultural singular, no solo de las Bahamas, sino que, además de compartir un origen común con "características constructivas y estilísticas" de las tradiciones edilicias en el Caribe angloafricano y las colonias inglesas en Norteamérica, constituyen un legado de alcance regional.

En una serie de talleres de dibujo y proyecto en la Facultad de Arquitectura de la Universidad de Miami se viene estudiando el legado histórico cultural de la arquitectura y urbanismo del Gran Caribe. En particular, las tradiciones edilicias del Caribe anglo-africano. Si en un primer momento nuestro enfoque estaba centrado en la preservación de este patrimonio, este interés se transformó, por las lecciones dadas, en el estudio de las características constructivas de la experiencia de nuestros antepasados, por su mayor resiliencia y correspondencia con el medio. Entre estas características encontramos, como fundamental, el cuidado en la selección del lugar de asentamiento. La posición de la trama urbana, su geometría y escala, fue uno de los factores principales en la mitigación de destrucción de la tormenta. Otro aspecto importante es el reconocimiento de la importancia de la geografía hidráulica del litoral isleño, su geología, patrones de vientos y, además, sorpresivamente, la incorporación en la construcción de materiales procedentes del medio. La piedra caliza oolítica, natural del arrecife, y la arena de las dunas, con su constituyente paisajista, contribuyeron tanto al remate de la marejada como a su disipación. Una tercera lección es el uso de la construcción de marco de madera, que ofrece como material y método de construcción, más allá de la tolerancia a la salinidad, obvia consideración, un nivel de elasticidad y flexibilidad estructural graduable a la velocidad y fuerza lateral de los vientos.

Cómo entonces se podrían documentar estos asentamientos es la consecuente pregunta. Hoy en día nuevas tecnologías pueden facilitar considerablemente la documentación del edificio, desplazamiento urbano y condiciones medio ambientales. Imágenes en 2D y 3D se pueden producir con mayor rapidez, precisión y de forma más económica que nunca. Con el acceso a los sistemas de posicionamiento global, con el software de procesamiento de gran alcance, y con el hardware fácilmente disponible una enorme cantidad de datos pueden ser recopilados y transformados a aplicaciones utilizables.

Por otra parte, estas nuevas tecnologías no sustituyen a los métodos tradicionales de grabación de estructuras históricas. La estabilidad de archivo de datos digitales es incierta, es deficiente en comparación a la estabilidad, de 500 años o más, de dibujos mecánicos producidos en tinta, ya sea en lienzo o mylar. Pero nuevas tecnologías ofrecen niveles elevados de precisión y facilidad en la 
interpolación de los datos, ya sea térmica, climatológica, o densidad de materiales en el medio o desplazamientos de bancos de arena, como ejemplo.

Un avión no tripulado equipado con cámara digital puede recolectar millones de píxeles de alta resolución, que se pueden transcribir a dibujos por ordenadores utilizados comúnmente en la arquitectura y la construcción. El proceso de documentación, sin embargo, aún requiere que una persona deba observar, analizar y componer dibujos de una forma precisa y completa.

En conclusión, creemos que, para el estudio y la documentación, el arquitecto, urbanista o paisajista puede integrar nuevas herramientas tecnológicas en su proceso tradicional de trabajo. La alta resolución digital de la ortofotografía, los levantamientos topográficos y las nubes de puntos complementan el conjunto de información que hasta ahora se obtenía de forma manual y dispersa. Y si esos datos pueden ser archivados en un formato fiable y estable facilitaría un nivel de interfaz adecuado para el acceso a múltiples escalas de dibujos y diversos tipos de información que nos aproxime a la resiliencia y sostenibilidad ambiental y cultural que demuestra el patrimonio cultural edilicio de nuestras respectivas tradiciones. 